\title{
UNSUR RELIGIUS (AQIDAH, SYARIAH DAN AKHLAQ) TOKOH SARITEM DAN SUKIRMAN DALAM NOVEL "KELIR SLINDET" KARYA KEDUNG DARMA ROMANSHA
}

\author{
Jufri Harbelubun \\ (Pendidikan Bahasa dan Sastra Indonesia, Fakultas Keguruan dan Ilmu Pendidikan, \\ Universitas PGRI Adi Buana Surabaya) \\ jufri@gmail.com
}

\begin{abstract}
ABSTRAK
Tujuan penelitian ini adalah mendeskripsikan nilai-nilai religius (akhlak, akidah, Syariah) Tokoh Saritem Dan Sukirman yang terdapat dalam novel Kelir Slindet Kedung Darma Romansha karya. Penelitian ini menggunakan metode deskriptif kualitatif untuk menganalisis data. Penelitian kualitatif digunakan untuk memperoleh gambaran empiris tentang religiositas dalam novel. Metode yang digunakan dalam penelitian ini adalah metode closereading yang akan digunakan dalam penelitian ini adalah teknik membaca dan mencatat langkah-langkahnya. dan sebagai objek penelitian adalah novel Kelir Slindet. Hasil penelitian penulis menyimpulkan bahwa nilai-nilai novel religi Slindet Kelir Kedung karya Darma Romansha meliputi Nilai pendidikan agama Islam berupa akhlak, aqidah dan syariah.: Nilai akhlak tercela meliputi Nelembuuk, judi, minum, Nilai syariah meliputi shalat, doa, pertobatan. Nilai akidah meliputi, keimanan kepada Tuhan; iman pada malaikat; iman dalam buku; dan iman Rasul.
\end{abstract}

Kata Kunci : Nilai Religius, Moralitas, Aqidah, Syariah, Kelir Slindet.

\section{PENDAHULUAN}

Karya Novel yang memiliki nilai religius sangat perlu dizaman sekarang ini, penting untuk menyadarkan kepada umat manusia akan sebuah kebenaran sejati yang sesungguhnya dari Allah, terutama pada zaman globalisasi sekarang ini agar dapat membentuk sikap dan mentalitas kepribadian yang dewasa.

Disini penulis menyampaikan kepada pembaca mengenai sebuah Novel yang berjudul Kelir Slindet, Oleh Kedung Darma Romansha. Dalam Novel ini menceritakan tentang sebuah potret kelam masyarakat desa yang terjebak dalam budaya dan mentalitas kemiskinan struktural. Budaya dan mentalitas "psangan saritem dan sukirman" yang telah melanggengkan kemiskinan, kejumudan, kemaksiatan, dan kemudaratan yang berkelindan dari generasi kegenerasi.

Keberhasilan penulis merekonstruksi "realita" kelam tersebut hanya bisa dicapai oleh penulis yang (pernah) menjadi bagian dari dan merasakan secara langsung ritme kehidupan mereka; disamping itu, tentu saja memiliki kualitas emosional yang begitu terjaga dalam proses kreatif penulis.

Berdasarkan cerita dari Novel Kelir Slindet, penulis sangat tertarik untuk mengkaji isi dari novel yang memiliki nilai religius dan manfaat yang sangat besar bagi ketangguhan Imanbagi pembaca. Dengan demikian, penulis merasa sangat perlu diadakan pengkajian atau penelitian terhadap karya sastra Novel " Kelir Slindet " karya Kedung Darma Romansha sebagai pembelajaran yang bermanfaat bagi pembaca.

Di dalam Novel " Kelir Slindet" karya Kedung Darma Romansha, penulis mengangkat judul tentang unsur nilai religius. Novel tersebut merupakan salah 
satu novel yang bersifat religius yang membangun iman, memberikan kesadaran, menumbuhkan semangat, dan pengetahuan yang dapat dijadikan acuan dalam kehidupan pembaca.

Berdasarkan latar belakang masalah tersebut di atas, dapat ditentukan rumusan masalah. Bagaimanakah deskripsi unsur religius (aqidah, syariah dan akhlak) Tokoh Saritem dan Sukirman dalam novel "Kelir Slindet" Karya Kedung Darma Romansha?

Tujuan penelitian ini yaitu untuk mendeskripsikan unsur religius (aqidah, syariah dan akhlak) Tokoh Saritem dan Sukirman yang terkandung dalam novel "Kelir Slindet" karya Kedung Darma Romansha dengan mencermati unsur-unsur pembangun secara totalitas.

\section{METODE PENELITIAN}

Dalam penelitian ini menggunakan deskriptif kualitatif. Penelitian kualitatif dipergunakan untuk memperoleh gambaran empiris mengenai religiusitas dalam novel.

Metode closereading yang akan digunakan dalam penelitian ini adalah teknik membaca dan mencatat. Metode closereading ini pada dasarnya hanya digunakan pada tahap analisis novel serta pencarian data penguat atau referensi untuk memperkuat atau membantu dalam proses penganalisisan novel.

\section{HASIL PENELITIAN}

1. Unsur Instrinsik

a. Latar

Novel ini menggunakan latar di warung, mushola, rumah Safitri, rumah Haji Nasir dan kuburan. Semua tempat tersebut berada di daerah Cikedung. Sehingga pada dasarnya, novel ini menggunakan latar tempat di Cikedung. Hal ini terdapat di kalimat: "Angin dari utara mendorong pohon-pohon di tepi jalan raya Cikedung." (Romansha, 2014:8). mengangkat cerita tentang kehidupan masyarakat desa yang terjebak dalam budaya dan mentalitas kemiskinan structural budaya dan mentalitas yang telah melanggengkan kemiskinan, kejumudan, kemaksiatan, dan kemudaratan yang berkelindan dari generasi ke generasi. Pada bagian awal novel Kedung Darma Romansa mencoba menggambarkan realita soaial yang terjadi pada masyarakat aslli disana, Setting dunia agraris sangat detail. Suasana kampung dijelaskan apik. Dirajut dengan konflik dan budaya agraris: pertelembukan, pentas dangdut, goyangan biduanita, orang-orang bergunjing. Bagaimana Saritem melabrak Haji Nasir dan mengata-ngatai dengan cacian kasar adalah gaya ibu-ibu kampung bertengkar dan meluapkan kekesalan. Lalu kata-kata kasar dan makian yang disajikan tanpa sensor, menambah suasana 'ndeso' dalam novel ini. Ke'ndeso'an juga tampak dari banyaknya tokoh yang hadir, seperti menegaskan orang desa grubyak-grubyuk. Banyak sekali tokoh, seperti kehidupan desa.

b. Tema

Tema merupakan gagasan dasar yang menopang sebuah karya sastra dan yang terkandung di dalam teks sebagai struktur semantis dan yang menyangkut persamaan-persamaan atau perbedaan-perbedaan. Tema dalam sebuah cerita bersifat mengikat karena tema tersebut yang akan menentukan hadirnya peristiwa- 
peristiwa, konflik dan situasi tertentu. Adapun tema yang terdapat dalam novel Kelir Slindet Tema novel ini tentang cinta yang tak sampai karena perbedaan status sosial yang menghalangi untuk bisa bersama.

\section{Unsur Ekstrinsik (Exstrinsic)}

a. Emosi keagamaan atau getaran jiwa menyebabkan manusia menjalankan kelakukan keagamaan yang menyebabkan kelakuannya mempunyai nilai keramat atau sacret value. Pada cerita novel Kelir Slindet ini menjelaskan bahwa emosi keagamaan yang terletak pada Safitri. Meskipun anak dari keluarga telembuk namun Safitri masih mempunyai keimanan dan ketaqwaan. Sistem kepercayaan atau bayangan manusia tentang bentuk-bentuk dunia, alam gaib dan alam maut. Unsur ekstrinsik ini terdapat pada peran Haji Nasir meskipun bergelar haji namun warga mengatakan kalau haji Nasir percaya dengan hal mistik, yaitu memelihara tuyul, da nada pula yang mengatakan punya perjanjian engan Nyi Blorong.

b. Sistem upacara keagamaan yang bertujuan mencari hubungan dengan dunia gaib. Dalam hal ini sistem upacara keagamaan yang dianutnya adalah Upacara Mapag sri atau biasa dikenal dengan menyambut musim panen, warga wujud syukur atas limpahan penen tahun ini, meskpiun tidak sesukses tahun -tahun yang lalu (Romansha, 2014:85).

c. Kelompok keagamaan atau kesatuan sosial yang mengkonsepkan dan mengaktifkan religi. Dalam hal ini kelompok keagamaan yang dianutnya adalah keagamaan islam. Yang meliputi kegiatan mengaji rutin di Mushola, kegiatan Qasidah, dan Majlis Mushola lainnya.

\section{PEMBAHASAN}

\section{Nilai Akhlaq}

Merupakan buah Islam yang bermanfaat bagi manusia dan kemanusiaan serta membuat manusia hidup dan kehidupan menjadi baik. Akhlak merupakan alat kontrol phisis dan sosial bagi individu dan masyarakat. Akhlak atau moral merupakan pendidikan jiwa agar jiwa seseorang dapat bersih dari sifat-sifat yang tercela dan dihiasi dengan sifat-sifat terpuji, seperti rasa persaudaraan dan saling tolong-menolong antar sesama manusia, sabar, tabah, belas kasih, pemurah dan sifat-sifat terpuji lainnya, Masyhur Amin1997. Sebagaimana yang tertuang dalam Novel :

"Mukimin mengendap - endap kea arah jendela mushola untuk mengintip kecantikan Safitri. (Romansha, 2014: 5).

Dialog tersebut dengan jelas memperlihatkan akhlaq tercela yaitu mengintip kecantikan Safitri yang merupakan bukan muhrim dari seorang laki laki. Berdasrakan Hadis Rasulullah SAW mengatakan Katakanlah kepada lakilaki yang beriman: "Hendaklah mereka menahan pandangannya, dan memelihara kemaluannya; yang demikian itu adalah lebih suci bagi mereka, sesungguhnya Allah Maha Mengetahui apa yang mereka perbuat". (Q.S. 24/an-Nûr:30).

Dialog tersebut di perkuat sebagai berikut :

"Saritem seorang telembuk (Pekerja Seks Komersial) lebih tepatnya mantan telembuk. Saritem menghentikan profesinya sebagai telembuk terkadang datang ke mushola Haji Nasir hanya ingin mengharap pujian 
dan dianggap bertobat. Namun cara dandannya masih menor, dan berpakaian kadang juga tak singkron. (Romansha, 2014: 19).

Dan Sikap Sukirman yaitu "Sukirman petani kecil suka mabuk, doyan telembuk, dan lebih menghabiskan uang di panggung hiburan”. (Romansha, 2014: 20).

Berdasarkan sikap Saritem dan Sukirman tersebut merupakan Zina Muhsan Yaitu lelaki atau perempuan yang telah pernah melakukan persetubuhan yang halal (sudah pernah menikah). Perzinaan yang boleh dituduh dan didakwa dibawah kesalahan Zina Muhsan ialah lelaki atau perempuan yang telah baligh, berakal, merdeka dan telah pernah berkahwin, iaitu telah merasai kenikmatan persetubuhan secara halal. Akibat yang paling fatal bagi semua orang yang berzina adalah akan terjangkitnya penyakit AIDS. Penyakit kelamin yang menyengsarakan fisik, mental, social. Secara fisik biologis, seseorang yang terinfeksi firus HIV akan kehilangan system kekebalan tubuh untuk melawan penyakit secara berlahan.

Dari potongan dialog diatas, memberikan informasi kepada masyarakat umat islam bahwasannaya janganlah pernah meremehkan orang lain karena kita belum tentu lebih baik dari orang yang kita remehkan.

Adapun sikap dari Saritem terhadap Safitri yang begitu kurang sopan, sehingga berdampak pada anaknya Safitri yang semula lugu dan polos, sebagai berikut :

"Saritem jengkel. Dia berdiri dan mendekati kamar Safitri, saritem menggedor-gedor kamar itu dengan keras. "Fit",", teriaknya lagi. Maka ia buka kamar Safitri, masuk dan mematikan tape. " ngapain kamu jogetjoget seperti itu?! Mau jadi berandalan?! Koplok! “ Saritem pandangi tubuh Safitri yang sudah basah kuyup. "emak banyak omong, ah! Orang lagi enak-enak nembang juga, malah di ganggu." (Romansha, 2014: 127).

Berdasarkan dialog tersebut dapat di ketahui bahwa setiap perkataan orang tua merupakan doa bagi anak-anaknya. Hendaknya orang tua memiliki sikap yang baik tutur bahasa yang sopan sehingga dapat jadi panutan bagi anakanaknya,adapun peribahasa yang mendukung adalah Buah Jatuh Tak Jauh Dari Pohonnya.

Prasangka buruk termasuk sifat dan akhlak buruk yang tercela dan alQuran memperingatkan manusia agar berhati-hati tidak sampai terkena penyakit ini.

Secara umum, prasangka buruk dapat dibagi menjadi tiga kategori:

1. Prasangka buruk terhadap diri sendiri (nafs ammarah).

2. Prasangka buruk terhadap orang lain.

3. Prasangka buruk kepada Allah.

Berdasarkan dialog tersebut diatas mengenai nilai religi yang terkandung dalam novel kelir slindet yaitu Nilai Akhlaq merupakan perkara-perkara yang dipercayai dan diyakini kebenarannya dalam Islam, berdasarkan dalil alQur'an dan Sunnah Rasul. Kurangnya pengarahan tentang akhlak mulia menjadi faktor utama penyebab generasi muda tidak menerapkan akhlak mulia dalam kehidupannya sehari-hari. Memang sulit menyadari bahwa kita tidak menerapkan 
akhlak mulia. Namun, orang yang ada di sekeliling kita merasakan bahwa kita tidak bersikap baik pada mereka. Hal ini, juga menyebabkan hidup kita menjadi tidak nyaman dan damai. Karena setiap orang yang telah kamu perlakukan tidak baik akan selalu menghindari darimu dan kemungkinan memiliki perasaan dendam padamu. Karena sikapmu yang tidak baik padanya.

Akhlak mulia merupakan salah satu nilai luhur. Nilai luhur perlu ditanamkan sejak dini dan diterapkan dalam kehidupan sehari-hari. Nilai juga merupakan alat solidaritas yang mendorong kita untuk bekerja sama dan mengarahkan kita untuk berpikir positif. Nilai merupakan gambaran yang mengenai apa yang di inginkan, yang pantas, yang berharga, dan yang mempengaruhi orang yang memiliki nilai itu (Robert M.Z. Lawang: 47-2006).

\section{Nilai Aqidah}

Aqidah merupakan keimanan yang teguh dan bersifat pasti kepada Allah dengan segala pelaksanaan kewajiban, bertauhid dan taat kepada-Nya, beriman kepada Malaikat-malaikat-Nya. Rasul-rasulnya kitab-kitab-Nya, hari Akhir, takdir baik dan buruk dan mengimanai seluruh apa- apa yang telah shahih tentang Prinsip-prinsip Agama (Ushuluddin), perkara--perkara yang ghaib, beriman kepada apa yang menjadi Ijman' (konsensus) dari Salafush Shalih, serta seturuh berita-berita qath'i (pasti), baik secara ilmiah maupun secara amaliyah yang telah datetapkan menurut A!-Qur'an dan As-Sunnah yang shahih serta ijma' Salafush Shalih.

Al Qur'an al karim telah menjadikan rahasia kebaikan yang menjadikan umat Islam istimewa adalah karena ia mengajak kepada kebaikan dan mencegah kemungkaran, dan beriman kepada Allah: "Kamu adalah umat yang terbaik yang dilahirkan untuk manusia, menyuruh kepada yang ma'ruf, dan mencegah dari yang munkar, dan beriman kepada Allah". (QS. Ali Imran: 110).

Dapat diketahui bahwasannya Allah SWT mengingatkan kita dalam AlQur'an bahwa keshalihan pribadi seseorang dalam kekhusyu'an beribadah kepada Allah belum bisa membuatnya mendapatkan keberuntungan sebelum kita mau peduli terhadap sesama kita. Hal ini bisa kita renungkan dalam firman-Nya, "Tahukah kamu orang yang mendustakan agama? Itulah orang yang menghardik anak yatim. Dan tidak menganjurkan memberi makanan orang miskin. Maka kecelakaanlah untuk orang-orang yang shalat. (yaitu) orang-orang yang lalai dari shalatnya. Orang-orang yang berbuat riya. Dan enggan menolong dengan barang yang berguna." (QS. Al-Ma'un ayat $1-7$ ).

Dapat diketahui bahwasannya pemimpin yang baik yaitu; pemimpin yang akan selalu tunduk dan patuh kepada Allah, dan hukum-hukum yang disyariatkanNya, yang membela dan menegakkan kebenaran, yang berani mengajak dan menyuruh mengerjakan yang ma'ruf, dan pemimpin yang berani mencegah serta memberantas segala bentuk kemunkaran dan kemaksiatan. Ia bekerja atas dasar karena melaksanakan tugas risalah Allah, yakni sebagai khalifah-Nya di muka bumi, untuk membangun kemakmuran bersama.

\section{Nilai Syariah}

Nilai Syariah merupakan suatu nilai Syariat Islam adalah wahyu Allah yang diturunkan kepada Rasulullah untuk disampaikan kepada umatnya. Ia bukan sebuah teori, akan tetapi merupakan ajaran ilahi yang harus dipalajari, dan 
diberlakukan untuk menciptakan keteraturan dalam kehidupan masyarakat serta keseimbangan antara kewajiban dan hak. Syariat Islam akan berlaku bagi semua umat manusia di dunia sampai akhirat, tetapi bila syariat Islam dijadikan hukum positif disuatu negara, maka keberlakuannya hanya bagi masyarakat Islam.

Berdasarkan nilai syariah islam tersebut diatas, dapat disimpulkan bahwa niali syariah yang terkandung dalam novel kelir slindet diantaranya syariah yang berhubungan dengan Allah, dan Syariah yang berhubungan dengan manusia. Namun nilai syariah yang terkandung pada novel tersebut masih minim sekali. Dan mayoritas masyarakat masih dalam kehidupan jahiliyah atau zaman kebodohan, yang mana masih berbuat yang dilarang oleh agama.

\section{SIMPULAN}

Dari uraian hasil pengkajian dan pembahasan skripsi ini, maka dapat menarik beberapa kesimpulan sesuai dengan rumusan masalah penelitian, bahwa Unsur religius (Akhlaq, Aqidah dan Syariah) Tokoh Saritem dan Sukirman dalam novel "Kelir Slindet" Karya Kedung Darma Romansha sebagai berikut:

1. Nilai Akhlaq. Akhlaq berasal dari kata Khalaqa yang kata asalnya Khuluqun yang berarti perangai, tabiat. Jadi secara etimologi akhlaq itu sebagai perangai, adat, tabiat, perangai atau sistem perilaku yang dibuat oleh manusia. Nilai akhlaq yang peneliti temukan dalam novel Kelir Slindet yiatu tentang larangan Allah SWT, tutur kata dan perilaku tercela, sabar, sopan santun, serta akhlaq bermasyarakat. Pada larangan Allah SWT ditemukan pada tokoh Saritem sebagai seorang telembuk serta Sukirman yang suka doyan mabuk, telembuk dan lebih menghabiskan uang di panggung hiburan. Pada akhlaq sabar ditemukan pada tokoh Safitri yang sabar serta Musthafa. Pada akhlaq tercela ditemukan pada tokoh Beki, Kartam, Kriting, Govar dan Casta yang suka mengambil barang yang bukan miliknya seperti mengambil mangga di pekarangan haji Caca.

2. Nilai Aqidah. Sistem kepaercayaan Islam atau akidah dibangun di atas enam dasar keimanan yang lazim disebut Rukun Iman. Rukun Iman meliputi keimanan kepada Allah,malaikat, kitab-kitab, rasul, haru akhir dan qodha dan qadar. Nilai Aqidah yang peneliti temukan dalam novel ini adalah mengenai pesan aqidah, pesan moral, bersyukur dalam kondisi apapun, budi pekerti yang luhur serta mengEsakan Allah SWT. Pada nilai aqidah yang suka bersyukur ditemukan pada tokoh Safitri, Musthafa

3. Nilai Syariah. Syariah yang berisi peraturan dan perundang-undangan yang mengatur aktifitas yang seharusnya dikerjakan dan yang tidak boleh dikerjakan manusia. Syariat adalah sistem nilai Islam ditetapkan oleh Allah sendiri dalam kaitan ini Allah disebut sebagai Syaari' atau pencipta hukum. Nilai syariah yang peneliti temukan pada novel kelir slindet adalah syariat yang mengatur hubungan dengan manusia secara horizontal dengan sesama manusia dan makhluk lainnya, disebut muamalah. Muamalah meliputi ketentuan atau peraturan segala aktivitas hidup manusia dalam pergaulan dengan sesamanya dan dengan alam sekitarnya. Larangan nilai syariah ditemukan pada tokoh mukimin dan safitri saat bertemu di warung Yu Tini serta saat sabung ayam, mengEsakan Allah SWT ditemukan pada tokok safitri yang bergabung dalam grup kasidah pimpinan Musthafa. 


\section{SARAN}

Setelah mengadakan kajian tentang nilai - nilai pendidikan Agama Islam dalam Novel Kelir Slindet dan relevansinya terhadap pendidikan Agama Islam, ada beberapa saran yang penulis sampaikan adalah sebagai berikut :

1. Kepada Kedung Darma Romansha, penulis mohon untuk konsisten memasukkan nilai - nilai Pendidikan Agama Islam dalam menulis novel guna memberikan nilai lebih pada karya sastra yang tidak hanya menghibur tetapi juga mendidik dan dalam alur ceritanya pun mohon diiringi dengan hal - hal yang sekiranya lebih menarik supaya pembaca tidak bosan untuk membacanya.

2. Bagi mahasiswa yang akan melakukan penelitian literature supaya lebih teliti dan lebih selektif dalam memilih novel yang akan di kaji sebab isi novel merupakan manifestasi dari kematangan berpikir seorang pengarang, maka pilihlah pengarang yang sudah matang pikirannya, keilmuan maupun pengalaman hidupnya.

3. Kepada pembaca khususnya para remaja amanat yang dapat disampaikan pada novel kelir slindet ini bahwa kita harus selalu berhati-hati dalam bergaul. Novel ini juga menyampaikan bahwa segala sesuatu tidak boleh dilakukan dengan tergesa-gesa. Karena semua ada pada waktunya. Kita juga tidak boleh membeda-bedakan sesama umat manusia.

\section{DAFTAR PUSTAKA}

Ahmad Warson Munawir, 1997, Kamus al-Munawir, Pustaka Progresif, Surabaya, cet..XIV.

Abdu al-Ghoniy Abud, 1992, Aqidah Islam versus Ideologi Modern, terj. Kathur Suhardi, Trimurti Press, Ponorogo.

Ahmad Amin, 1975, Etika Ilmu Akhlak, Jakarta: Bulan Bintang.

Ball, J. Van. 1971. Symbols for Communication : An Introduction to the Anthropological Study of Religion. Assen: van Gorcum \& Company N.V.

Chabib Thoha, 1999, Metodologi Pengajaran Agama, dalam Pengajaran Akhlak Semarang: Fakultas Tarbiyah IAIN Walisongo.

Cyriil, Glasse, 1996, Ensiklopedi Islam, P.T. Raja Grafindo Persada, Jakarta, cet.I, 1996.

Hamzah Ya'qub, 2006, Pemurnian Aqidah dan Syari'ah Islam, CV. Pedoman Ilmu Jaya, Jakarta.

Hakeem Abdul Hameed, 1983, Aspek-Aspek Pokok Agama Islam, terj. Ruslan Shiddiq, P.T. Dunia Pustaka Jaya, Jakarta, cet.I.

Hadikusuma, Hilman, 2003, Hukum Waris Adat, Citra Aditya Bakti, Bandung.

Koentjaraningrat, 1974, Kebudayaan Mentalitas dan Pembangunan, Gramedia Pustaka Utama, Jakarta.

Masyhur Amin, 1997, Dakwah Islam dan Pesan Moral, Yogyakarta: Al Amin Press, Cet. I.

Muslim Nurdin, et.al., 1995, Moral dan Kognisi Islam, CV. Alfabeta, Bandung, cet.II. 
Omar Mohammad Al-Toumy Al-Syaibany, 1979, Falsafah Pendidikan Islam, Jakarta: Bulan Bintang, Cet. I.

Seyyed Hossein Nasr, ed., 2002, Ensiklopedi Tematis Spiritualitas Islam, Bandung: Mizan Media Utama, Cet. II.

Yunahar Ilyas, Kuliah Aqidah Islam, 1993, Lembaga Pengkajian dan Pengamalan Islam, Yogyakarta, cet. II.

Zaky Mubarok, et.al., 2001, Akidah Islam, UII Press, Yogyakarta, cet.II. 